\title{
Reshuffling Students to Fight Discrimination and Foster Pro-Social Behavior: A Field Experiment*
}

\section{Cómo luchar contra la discriminación y fomentar el comportamiento pro-social: una intervención en la composición de clases en la escuela}

\author{
Marina Bosque Mercader \\ CEMFI \\ Andrés Gago \\ Universidad Torcuato Di Tella
}

\begin{abstract}
There is substantial evidence that group identity shapes discrimination and pro-social behavior. Subjects tend to be more pro-social towards in-group members and discriminate out-group members. In this paper, we run a field experiment in a school in Barcelona to study whether belonging to the same class induces in-group favoritism. Moreover, we explore whether reshuffling students between classes is a good strategy to expand pro-social behavior within the school and fight discrimination. According to our results, participants allocate more resources, are more generous, retaliate less and give higher rewards to students who have always belonged to their same class relative to those who have never been part of it. Moreover, after varying the composition of classes, we find that new students in class start being considered group members and treated as so, while those that are not any longer in the same class do not lose their in-group status.
\end{abstract}

Keywords: group identity, dictator game, reciprocity, school, discrimination.

JEL Classification: I28, I29, D63, C90, C72.

\section{Resumen}

La identidad de grupo es un factor importante que incide en los comportamientos discriminatorios así como en las actitudes pro-sociales. Las personas tienden a comportarse de manera más pro-social con otros integrantes de su grupo y discriminan a aquellos que no pertenecen a su comunidad. En este artículo, a través de un experimento de campo en un colegio en Barcelona, estudiamos si pertenecer a la misma clase genera este tipo de identidad de grupo. Además, exploramos si variar la composición de las clases es una estrategia efectiva

* The authors are particularly grateful to Caterina Calsamiglia, Guillermo Caruana, Yan Chen, Sherry Xin Li, Laia Bosque and Manuel Arellano for their helpful comments and suggestions. We thank Laia Pemán, Laura Ruiz, Rosa Falgà, Oscar Alba and the rest of teachers and students from Aula Escola Europea for their collaboration to make this project possible. The authors acknowledge research funding support from Centro de Estudios Monetarios y Financieros (CEMFI). This project is based on CEMFI's Master Thesis Group Identity inside the School: Evidence from a field experiment in Barcelona (Marina Bosque Mercader, 2019). 
para diseminar el comportamiento pro-social y luchar contra la discriminación en la escuela. De acuerdo con nuestros resultados, los estudiantes discriminan positivamente a aquellos con los que han compartido clase en detrimento de aquellos que nunca han pertenecido al grupo, son más generosos con los primeros, menos vengativos, y premian más sus actitudes pro-sociales. De manera interesante, tras variar la composición de las clases, observamos que mientras los nuevos compañeros empiezan a ser tratados como miembros del grupo, aquellos que pertenecieron a la misma clase y ahora pertenecen a otra no pierden su estatus de miembros de la comunidad.

Palabras clave: identidad de grupo, juego del dictador, reciprocidad, discriminación en la escuela.

Clasificación JEL: I28, I29, D63, C90, C72.

\section{Introduction}

Would you prefer to share a beer with a supporter of your football team or with a supporter of the rival football team? Why would an economist trust more the evidence coming from another economist than a study conducted by a psychologist or a sociologist? Have you ever said: "My country is the best in the world!"? These are some examples of situations in which group identity shapes the way in which we think and act.

Social or group identity refers to a person's sense of belonging to a particular group. The feeling of attachment makes individuals follow the behavioral pattern of the group (Shih et al., 1999; Benjamin et al., 2010), prefer the aggregate benefit of the group (Halevy et al., 2008; Zdaniuk \& Levine, 2001; Van Vugt \& Hart, 2004) and exhibit more cooperation with in-group rather than out-group members (Goette et al., 2006). Group identity is a notion that is familiar to all of us and it is a central factor to understand social interactions in psychology, biology, sociology, anthropology, political science, and economics. Group membership leads to outgroup discrimination when adults distribute resources among third parties (Chen \& Li, 2009; Bernhard et al., 2006; Bernhard et al., 2006) and shapes their pro-social behavior (Chen \& $\mathrm{Li}, 2009)$. In this paper, we aim to contribute to this literature in two ways. First, we want to establish whether belonging to the same class in school generates group identification. To test this, we study whether children discriminate students who have never belonged to their class in favor of their classmates, and whether they are more pro-social when they interact with the later. Second, we want to explore whether reshuffling students between classes is an effective way to foster pro-social behavior in school and fight discrimination.

In order to shed light on these conjectures, we conduct an experiment among students of fourth and fifth of primary in a private school in Barcelona. Based on the experimental design developed by Chen and Li (2009) and redefined by Movahedi (2018), participants play three games that measure out-group discrimination and pro-social attitudes: an other-other allocation game, a dictator game, and a response game. We compare interactions with classmates and with students that have never belonged to the same class to study the influence of group identity in the preferences of participants. Moreover, we take advantage of a school policy which randomly 
reshuffles students into three newborn classes to understand if students consider new and former classmates as part of their group and behave accordingly.

In a population of adults, Chen and $\mathrm{Li}$ (2009) find that group membership shapes social preferences and determines how participants allocate resources. When we compare interactions between students who have never been in the same class with students that have always been classmates, results are aligned with those in Chen and $\mathrm{Li}$ (2009). We observe that when students have to allocate money between an ingroup and an out-group member, they discriminate negatively towards the out-groups. Moreover, we observe that when students have to allocate money between themselves and another student, they are more generous with the in-groups. Finally, we observe that when students have the possibility to reward or punish others for their actions paying a cost, they reward more and punish less when they interact with other ingroup students. Interestingly, we observe that after reshuffling students, participants treat new students in class as in-groups, while former classmates do not lose their ingroup status. This suggests that reshuffling students between classes could be a good policy to expand pro-social behavior and fight discrimination in school. ${ }^{1}$

From an academic perspective, these results contribute to the literature studying the implications of social identity. Social identity theory was first developed by the psychologists Tajfel and Turner (1979) in order to understand the reasons behind inter-group conflicts. According to their theory, group identity is based on three mental processes in which individuals divide the world between people considered us (in-group) and them (out-group): categorization, identification, and comparison. First, categorization is the process of assigning people into categories according to particular characteristics (gender, ethnicity, religion, politics, etc.). Second, identification is the process of associating ourselves with certain groups. Particularly, in-group members are defined as people who are associated with us, while out-group members are people who are not considered part of our group. Finally, comparison is the process of comparing the in-group members with another group, creating a positive bias toward the group one belongs to. The findings of Turner and Tajfel (1986) conclude that even trivial inter-group categorization leads to in-group favoritism and discrimination against the out-group. Since then, further evidence have been gathered both in social psychology (see for example Mullen et al., 1992; Brewer, 1999) and, more recently, in economics (e.g. Croson et al., 2008; Chen \& Li, 2009; Hargreaves Heap \& Zizzo, 2009; Sutter, 2009) pointing in the same direction. ${ }^{2}$

${ }^{1}$ Even if participants are always more generous, reward more often and are more lenient with students that at some point have been classmates, in some situations there are differences depending on whether they have always been in the same class or not. We will comment on these differences later. Regarding the allocation task, the only group that suffers negative discrimination is the one including students that have never been classmates, while the other groups are treated equally.

${ }^{2}$ It is worth mentioning that even if most of the literature has found in-group favoritism, some papers have found that in-group defectors are judged more negatively both among adults (e.g. Shinada et al., 2004; Marques et al., 1988) and young children (Schmidt et al., 2012; Abrams et al., 2014). This is known as the black sheep effect and it has been argued to help group maintenance. We find no evidence of such an effect, provided that in-group students in our study receive softer (not harsher) punishments when they behave selfishly. 
Unlike experiments that use trivial cues to group participants, in this paper we do not assign individuals to different groups using the minimal group paradigm (Tajfel, 1970). Instead, we take advantage of the random assignment mechanisms used by the school to establish the initial classes when students join school at the age of three, and the newborn classes in fifth grade. We think that this fact strengthens the external validity of the paper relative to a lab intervention with minimal groups, as it allows us to have exogenous variation in group formation without missing the social ties that typically arise in real groups. Moreover, Hartstone and Augoustinos (1995) claim that conclusions in the minimal group paradigm artificially rely on a dichotomous classification of subjects, and they show that results disappear once more than two groups are created. In our experiment, students can be classified in four groups depending on whether they share class until fourth grade, and whether they do it in fifth grade. This allows us to show that in real group environments individuals discriminate also in settings in which individuals are classified in several groups.

A complete discussion of the differences between real groups and minimal groups can be found in Goette et al. (2012). Interestingly, unlike Goette et al. (2006) and Goette et al. (2012), we do replicate the finding by Chen and Li (2009) that participants are more lenient towards in-groups. This casts doubt on the belief that once we move from minimal groups to real groups, leniency towards in-groups disappears (Goette et al., 2012). Relative to studies that use endogenously formed groups (see for example Bernhard, Fehr \& Fischbacher, 2006; Bernhard, Fischbacher $\&$ Fehr, 2006) our study allows us to capture the effect of group membership while we compare individuals that are rather similar and abstract from the confounding effect of self-selection into groups.

An important characteristic of our study is that our pool of subjects are children of 9-10 years old. Previous studies in social psychology have found that children as young as 6 years old show similar patterns of out-group discrimination in third party allocation games as those found in the adult population (Jordan et al., 2014). Similarly, Fehr et al. (2008) show that children at the age of 7-8 have already developed other-regarding preferences, i.e. they are willing to sacrifice resources to enhance the welfare of other individuals. Using laboratory and field experiments, Rao (2019) finds that after integrating poor students in elite private schools in India, rich students become more pro-social, generous and egalitarian. He also finds that it becomes less likely that they discriminate against other poor students and more likely that they socialize with them. We contribute to the literature by showing that group membership shapes pro-social preferences in 9 and 10-year-old children in a similar way as it does in adults. More importantly, we show that the pool of children that are considered as in-groups can be easily extended by reshuffling students between classes, as new classmates earn in-group status while former classmates do not lose it. 
In the remainder of the paper, Section 2 describes the experimental design in detail, Section 3 presents the results and Section 4 concludes.

\section{The Experiment}

This experiment is conducted with students of fourth and fifth of primary school in Aula Escola Europea, a private school in Barcelona. This school divides each cohort into three groups of approximately 34 students. The composition of these groups remains the same since the students start going to the school at the age of three until the students reach the age of ten (which corresponds to fifth grade). At fifth grade, the school implements a policy that randomly reshuffles students into three newborn classes that remain unaltered until secondary school. ${ }^{3}$

The unit of study considered are pairs of students who can be classified in different categories depending on the course. Any pair of students from fourth grade can be identified in one of these two categories: students who have always belonged to the same class (In-group) or students who have never belonged to the same class (Outgroup). Likewise, any pair of students from fifth grade can be classified in one of the following four categories: students who belong to the same class before and after the policy (In-group); students who do not belong to the same class before the policy and remain in different classes after the policy (Out-group); students who do not belong to the same class before the policy and start being in the same class after the policy (New-In-group); or students who used to belong to the same class before the policy and are not anymore in the same class after the policy (New-Out-group). The abovementioned categories are summarized in Figure 1.

Participants play three games that measure both how they allocate resources among third parties and different aspects of pro-social behavior: an other-other allocation game, a dictator game, and a response game. ${ }^{4}$ This games are based on Chen and $\mathrm{Li}$ (2009) and Movahedi (2018). We compare different pairings to explore how group identity affects participants' decisions.

\footnotetext{
${ }^{3}$ In particular, the school employs the following criteria: (1) divide the cohort between males and females and put them in alphabetical order, (2) use a random mechanism (that changes from year to year) to allocate students to the new groups and only if it is necessary (3) do adjustments to avoid bad dynamics in the new groups or to balance the groups in terms of ability. According to the school, there is typically no need to do any adjustments.

4 The games were presented in hypothetical terms. Given that the interest of the project is to find differences in behavior that depend on group status, there is no obvious reason why using an hypothetical approach would change the conclusions qualitatively. Following an educational criteria and only after the experiment was finished, each student was rewarded with an equal amount of sweets. This criteria was jointly agreed with the Ethics Committee of CEMFI and the School Board. When students joined the experiment, they were not aware of any future reward.
} 


\section{FIGURE 1}

\section{CATEGORIES OF PAIRS OF STUDENTS}

Fourth of Primary

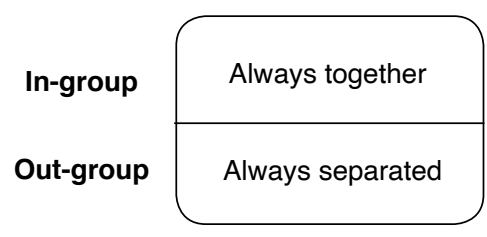

Fifth of Primary

\begin{tabular}{|c|c|c|}
\cline { 2 - 3 } In-group & Before policy & After policy \\
\cline { 2 - 3 } Out-group & Together & Together \\
Separated & Separated \\
New-In-group & Separated & Together \\
Tow-Out-group & Segether & Separated \\
\hline
\end{tabular}

\subsection{First Game: Other-Other Allocation Game}

In this game, participants are asked to allocate a given number of sweets between two other students from their cohort denoted as Player A and Player B. Participants cannot allocate any sweets to themselves. Depending on the relation between Player A, Player B and the allocator, this game considers four different identity combinations (see Figure 2). In order to observe if decisions are sensible to the size of the pie, we also consider three different amounts to divide: 10, 30 and 50 sweets. Provided that in fourth grade there are not New-In-group or New-Out-group categories, we have 3 observations of the other allocation game for each fourth grade student, whereas we have $12(4 * 3)$ observations for each fifth grade student.

FIGURE 2

\section{OTHER-OTHER ALLOCATION GAME}

Player A

In-group student

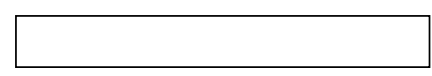

New-In-group student

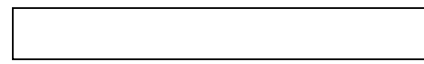

New-In-group student

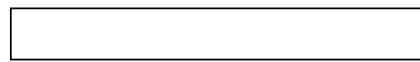

New-In-group student
Player B

Out-group student

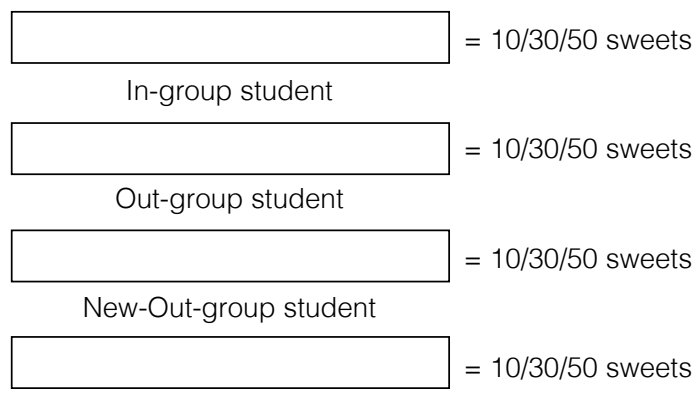




\subsection{Second Game: Dictator Game}

In this game, participants (the dictators) are asked to choose between two options to share a certain amount of sweets with another student of their cohort (the receiver). An illustration of this game is shown in Figure 3. Table 1 summarizes the four versions of this game that consider different allocation choices.

Participants in fourth grade play each version of the game both with an In-group and with an Out-group student, while participants in fifth grade play with an Ingroup, an Out-group, a New-In-group and a New-Out-group student.

FIGURE 3

DICTATOR GAME

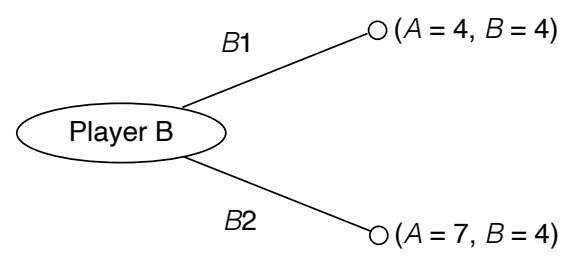

TABLE 1

DICTATOR GAMES

\begin{tabular}{|c|c|c|}
\hline & Option B1 & Option B2 \\
\hline DG1 & $(4,4)$ & $(7,3)$ \\
\hline DG2 & $(3,6)$ & $(7,5)$ \\
\hline DG3 & $(2,7)$ & $(6,6)$ \\
\hline DG4 & $(0,8)$ & $(4,4)$ \\
\hline
\end{tabular}

SOURCE: Based on Chen and Li (2009) and Movahedi (2018).

\subsection{Third Game: Response Game}

The Response Game is a two-person sequential move game. The first mover, Player A (the proposer), has two options: A1 or A2. If she chooses A1, the game ends with a particular allocation of sweets between herself and Player B. If she chooses A2, Player B (the respondent) decides how to allocate the sweets between options B1 and B2. An illustration of this game can be observed in Figure 4. In this game, participants are asked to play the role of the respondent and consider that the proposer always chooses the option A2. As we will see below, the choice of this option sometimes signals kindness and sometimes unkindness. 
FIGURE 4

\section{RESPONSE GAME}

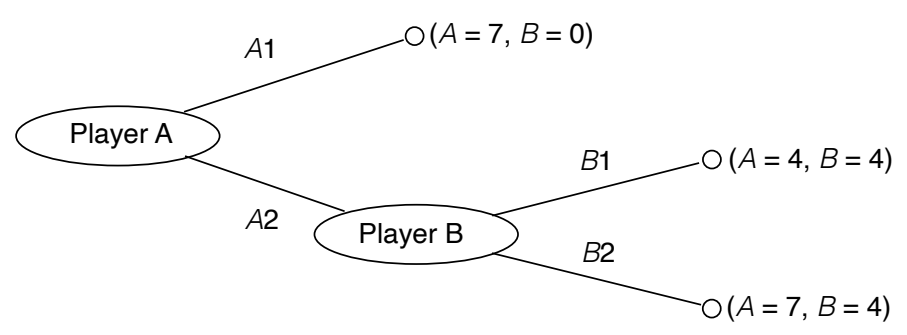

There are nine different versions of this game that consider different allocation choices (see Table 2). ${ }^{5}$ We divide the games in three categories: (a), (b) and (c). In categories (a) and (c), when Player A enters the game (i.e., chooses option A2), the payoffs for Player B are lower than if she stays out (i.e., chooses option A1). Conversely, in category (b), when Player A enters the game, payoffs for Player B are larger than if she stays out.

TABLE 2

RESPONSE GAMES

(a) Player B punishes Player A at no cost

\begin{tabular}{|l|c|c|c|l|}
\hline \multirow{2}{*}{} & \multirow{2}{*}{ A stays out } & \multicolumn{2}{|c|}{ A enters and B chooses: } & \multirow{2}{*}{ Associated with: } \\
\cline { 3 - 4 } & & Option B1 & Option B2 & \\
\hline RG1 & $(5,5)$ & $(4,4)$ & $(7,4)$ & negative reciprocity \\
\hline RG2 & $(4,9)$ & $(2,4)$ & $(4,4)$ & negative reciprocity \\
\hline
\end{tabular}

(b) Player B sacrifices her payoff to reward Player $A$

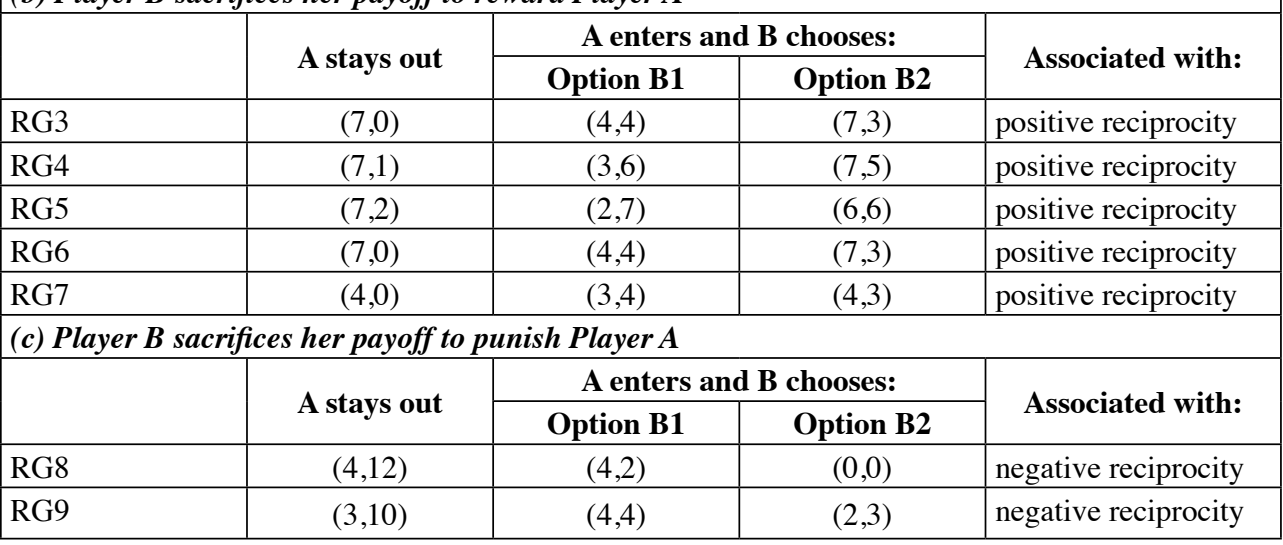

SOURCE: Based on Chen and Li (2009) and Movahedi (2018).

5 In this experiment, following Movahedi (2018), we decided to select those games whose results show the highest difference between in-group and out-group in Chen and Li (2009)'s experiment. 
We consider different reactions from Player B to Player A's choice. In the games included in category (a), Player B can decide to punish Player A at no cost. Conversely, in the games included in category (c), Player B needs to incur in a cost if she wants to penalize Player A's behavior. Analogously, in the games included in category (b), Player B needs to sacrifice her own self-interest to reward Player A.

Participants in fourth grade play each version of the game both with an In-group and an Out-group student, while participants in fifth grade play each game with an In-group, an Out-group, a New-In-group and a New-Out-group student.

\subsection{Experimental Procedure}

We conducted the experiment the $9^{\text {th }}$ and $10^{\text {th }}$ of May 2019 using $z$-Tree (Fischbacher, 2007). Forty-three students of fourth grade and eighty-eight students of fifth grade participated in the experiment. In order to maximize the number of observations, we used a within-subject design. All decisions taken by participants were anonymous. When participants took decisions, they were informed about the identity of the student they were playing with (name and surname). This conveyed the group categorization in an indirect way.

Before the experiment, all participants took a survey which asked them to name who their five closest friends are, their gender, their age and any extra-curricular activities they are involved in. This information complements the classification of couples of students into one of the four categories and takes into consideration that there might exist a close friendship between two students that do not belong to the same group. This allows us to reduce the variance and obtain more accurate estimators. Instructions were written to make sure that even children of 9-10 years old could understand the implications of the games. This forced us to be explicit, specially, in the reciprocity game. One could argue that this design choice of the instructions could generate demand effects for rewards and punishments. Provided that the focus of our paper is not on the existence of pro-social attitudes among young children (shown in Fehr et al., 2008), but on how pro-social attitudes are affected by group membership, we do not consider this to be a concern. An English version of the instructions and the survey questions can be found in Sections A3 and A4.

\section{Results}

\subsection{Other-Other Allocation Game}

In the other-other allocation game, we want to test two hypotheses. First, we want to understand whether the results in Chen and $\mathrm{Li}$ (2009) can be replicated in a school environment. In particular, we test whether being in the same class generates out-group discrimination. ${ }^{6}$ Second, we want to evaluate the policy intervention and

\footnotetext{
${ }^{6}$ Notice that in this experiment In-group favoritism implies Out-group discrimination and viceversa.
} 
understand if we can reduce discrimination by reshuffling students into different classes. Figure 5 plots the average allocation of sweets between In-group and Out-group students (y-axis), considering the three different amounts of sweets to divide (x-axis). The top panel shows the results in fourth grade, while the bottom panel shows the results in fifth grade. Results are consistent with class membership generating out-group discrimination. On average, participants allocate significantly more sweets to students who have always belonged to their same class.

Figure 6 evaluates the effect of the policy intervention. These figures compare the way participants allocate sweets between New-In-group members and students in the rest of the categories. The top panel presents the average allocation of sweets between a New-In-group and an In-group student; the panel in the middle presents the average allocation of sweets between a New-In-group and an Out-group student; and

FIGURE 5

RESULTS OTHER-OTHER ALLOCATION GAME

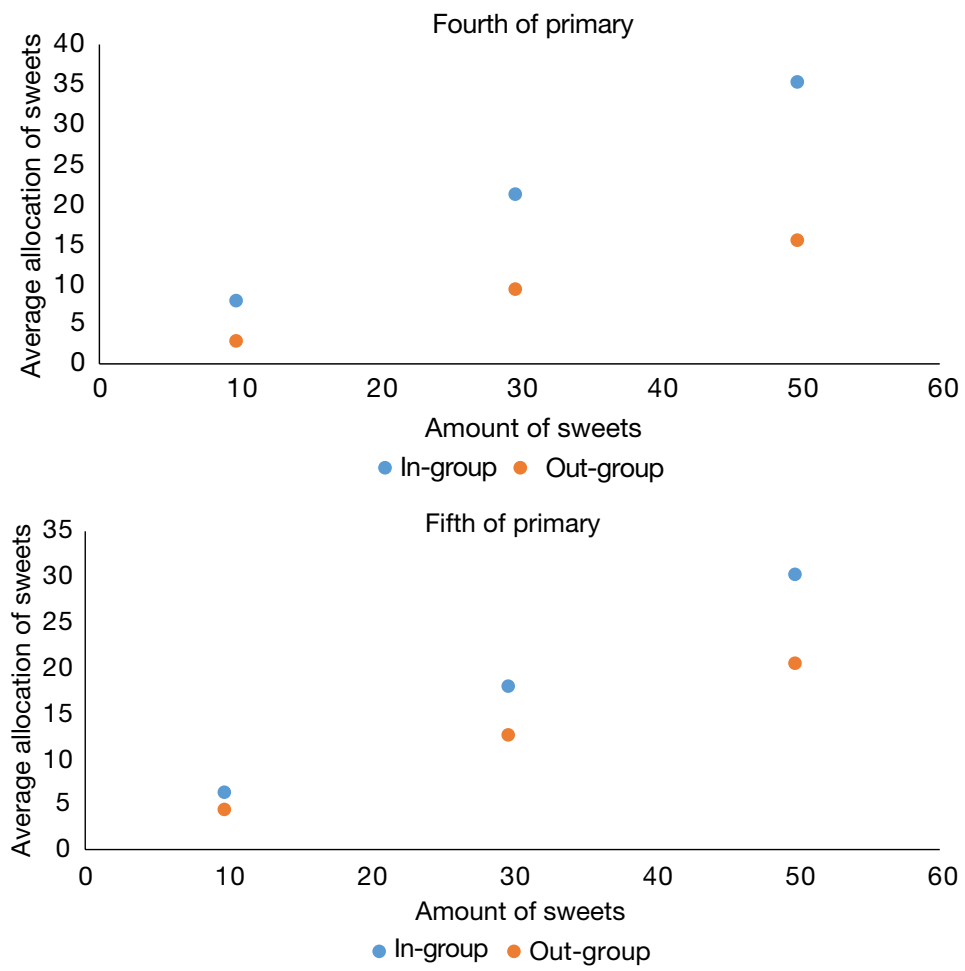

NOTE: The figure plots the average allocation of sweets between students of different categories (y-axis) and the different total amount of sweets to be allocated (x-axis). Blue circles represent the average amount of sweets allocated to In-group students and orange circles represent the average amount of sweets allocated to Out-group students. Symbols labeled as In-group refer to students who have always belonged to the same class as the player; and symbols labeled as Out-group refer to students who have never belonged to the same class as the player.

SOURCE: Own elaboration based on experimental data. 


\section{FIGURE 6}

\section{RESULTS OTHER-OTHER ALLOCATION GAME (FIFTH GRADE)}
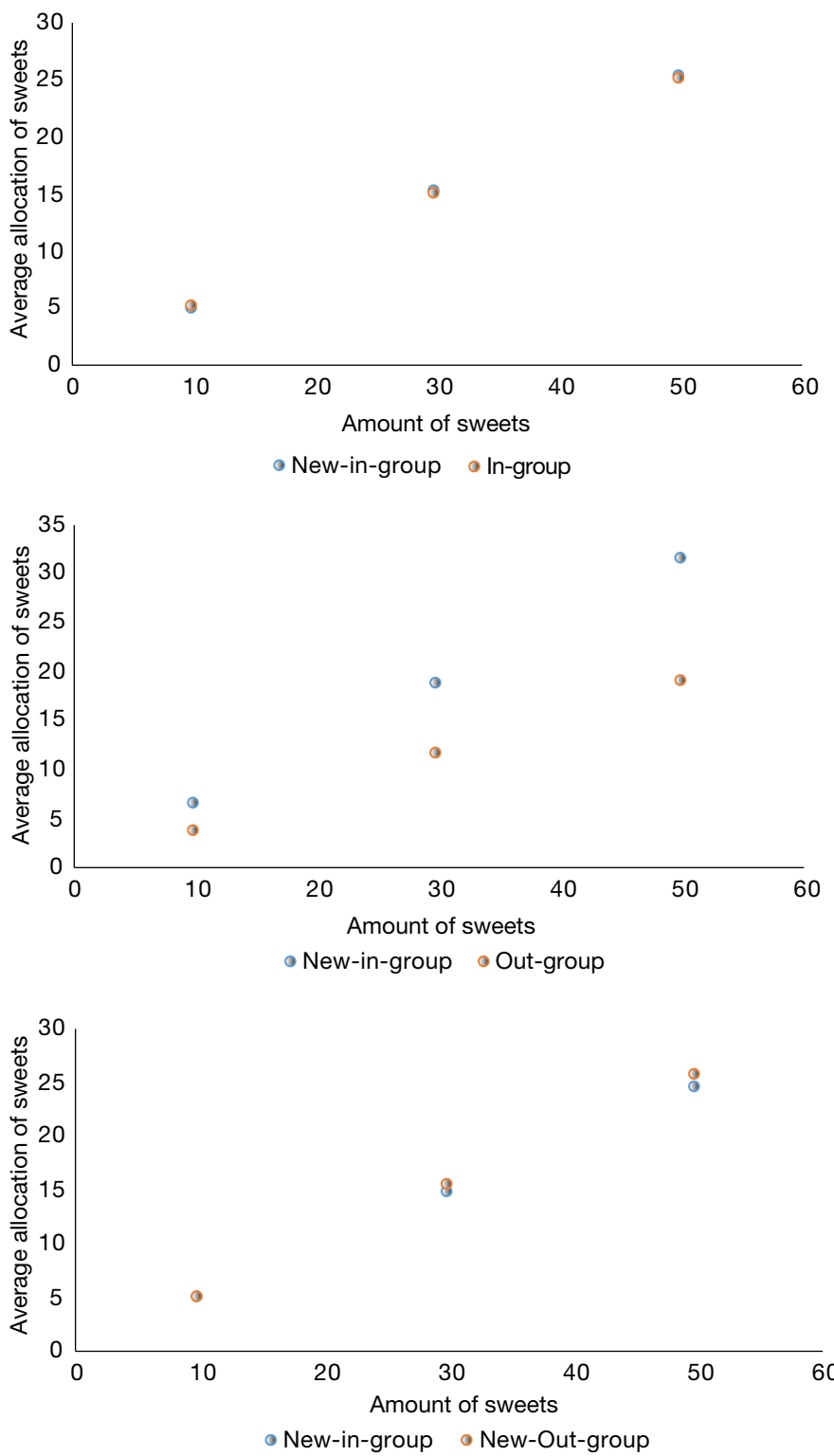

NOTE: The figure plots the average allocation of sweets between students of different categories ( $y$-axis) and the different total amount of sweets to be allocated (x-axis). Blue circles represent the average amount of sweets allocated to New-In-group students and orange circles represent the average amount of sweets allocated to In-group, Out-group or New-Out-group students. Symbols labeled as In-group refer to students who have always belonged to the same class as the player; symbols labeled as Out-group refer to students who have never belonged to the same class as the player; symbols labeled as New-In-group refer to students who have never belonged to the same class as the player, but after the policy started being in the same class; and symbols labeled as New-Out-group refer to students who have always belonged to the same class as the player, but after the policy stopped being in the same class.

SOURCE: Own elaboration based on experimental data. 
the bottom panel presents the average allocation of sweets between a New-In-group and a New-Out-group student. The results show no difference neither between NewIn-group and In-group, nor between New-In-group and New-Out-group, while they show a positive discrimination towards New-In-group relative to Out-group students. Hence, the graphical analysis suggests that one year after reshuffling students, (1) participants consider New-In-group students part of their group, while (2) they still treat New-Out-group as part of their group even if they are no longer in the same class.

Table 3 presents a formal analysis of the difference in the allocation of sweets between categories. This table displays the average number of sweets allocated to students depending on their category and the category of their pair relative to the allocator. When participants allocate sweets between an In-group/New-In-group and an Out-group student, the t-tests show they allocate more than half of the pie to the In-group/New-Ingroup student. On the contrary, when they allocate sweets between a New-In-group and an In-group/New-Out-Group, on average they equally split the number of sweets.

\section{TABLE 3}

\section{T-TESTS OTHER-OTHER ALLOCATION GAMES}

\begin{tabular}{|c|c|c|c|c|c|c|c|c|}
\hline & \multicolumn{4}{|c|}{ Fourth Grade } & \multicolumn{4}{|c|}{ Fifth Grade } \\
\hline Amount of sweets & 10 & 30 & 50 & Pooled & 10 & 30 & 50 & Pooled \\
\hline \multicolumn{9}{|l|}{ Categories: } \\
\hline In-group vs. Out-group & $7.44 * * *$ & $20.88^{* * * *}$ & $34.91 * * *$ & $0.71 * * *$ & $6.01 * * *$ & $17.64 *$ & $29.80^{* * * *}$ & $0.59 * * *$ \\
\hline & $(0.289)$ & $(0.902)$ & $(1.908)$ & $(0.016)$ & $(0.287)$ & $(0.798)$ & $(1.286)$ & $(0.014)$ \\
\hline New-In-group vs. In-group & & & & & $\begin{array}{c}4.89 \\
(0.276)\end{array}$ & $\begin{array}{c}15.09 \\
(0.836)\end{array}$ & \begin{tabular}{|c}
25.13 \\
$(1.412)$
\end{tabular} & $\begin{array}{c}0.50 \\
(0.015)\end{array}$ \\
\hline New-In-group vs. Out-group & & & & & $6.34 * * *$ & $18.53^{* * *}$ & $31.25 * * *$ & $0.63^{* * * *}$ \\
\hline & & & & & $(0.300)$ & $(0.842)$ & $(1.393)$ & $(0.016)$ \\
\hline New-In-group vs. New-Out-group & & & & & $\begin{array}{c}5.02 \\
(0.293)\end{array}$ & $\begin{array}{c}14.74 \\
(0.841)\end{array}$ & \begin{tabular}{|c|}
24.42 \\
$(1.352)$
\end{tabular} & $\begin{array}{c}0.49 \\
(0.016)\end{array}$ \\
\hline Observation & 43 & 43 & 43 & 43 & 88 & 88 & 88 & 88 \\
\hline
\end{tabular}

NOTE: The table displays the t-tests from the average amount of sweets which the players decide to give to a student from a specific category (corresponding to the first category mentioned in the column titled Category). In-group refers to games in which the player is interacting with a student who has always belonged to the same class as the player; Out-group refers to games in which the player is interacting with a student who has never belonged to the same class as the player; New-In-group refers to games in which the player is interacting with a student who has never belonged to the same class as the player, but after the policy started being in the same class; and New-Outgroup refers to games in which the player is interacting with a student who has always belonged to the same class as the player, but after the policy stopped being in the same class. Standard errors are in parentheses. ${ }^{*} p<0.10$, $* * p<0.05, * * * p<0.01$

SOURCE: Own elaboration based on experimental data.

Therefore, after analyzing the results in the other-other allocation game, we can conclude that there is discrimination within school on the grounds of class membership and that reshuffling students between classes is an effective way to fight against it.

\subsection{Dictator Game}

The dictator game measures whether subjects are willing to reduce their own wealth to favor others. In this game, we want to test whether students are more 
generous when they interact with another student who has always belonged to their same class than when they interact with a student who has never been part of it. Moreover, we want to understand whether reshuffling students into new classes is an effective way to expand the number of children affected by in-group generosity.

The first graph of Figure 7 shows the results of the dictator game from participants in fourth grade and the second graph shows the ones from participants in fifth grade. In particular, the figures present the proportion of times in which the participants choose the generous alternative (option B2 in Table 1) when they are interacting with a student who belongs to a particular category. ${ }^{7}$

FIGURE 7

\section{RESULTS DICTATOR GAME}
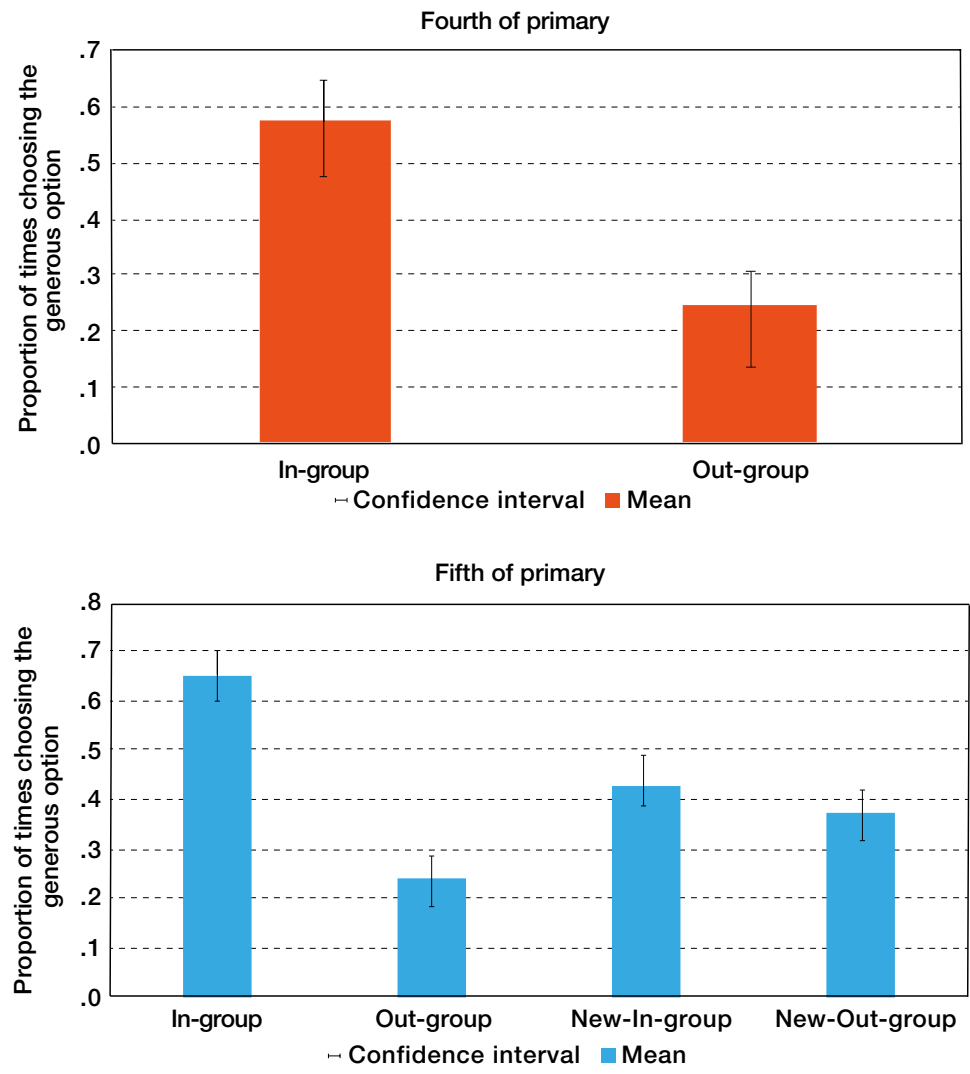

NOTE: The figure plots the average amount of times in which players choose option B2 (y-axis) and the category of the student who they are interacting with. The black brackets correspond to the confidence interval of the mean in each category. In-group refers to games in which the player is interacting with a student who has always belonged to the same class as the player; Out-group refers to games in which the player is interacting with a student who has never belonged to the same class as the player; New-In-group refers to games in which the player is interacting with a student who has never belonged to the same class as the player, but after the policy started being in the same class; and New-Out-group refers to games in which the player is interacting with a student who has always belonged to the same class as the player, but after the policy stopped being in the same class.

SOURCE: Own elaboration based on experimental data. 
We observe that more than $50 \%$ of students choose the generous option when they interact with an In-Group student. However, this proportion falls to around $40 \%$ when they interact with a New-In-group or a New-Out-group student. Finally, when participants interact with an Out-group student, this proportion barely exceeds $20 \%$. This provides evidence that group identity has an effect on generosity. Participants are almost three times more generous towards students that have always belonged to their same class than towards those with whom they have never shared class. Nevertheless, the effects of reshuffling students to foster generosity are somewhat mixed. Changes in class composition increases generosity towards students that used to be in the other class and are now in the same class, but this happens at the expense of students that used to be in the same class and are not anymore. In any case, generosity towards New-Out-group students is still sizable and significantly higher than towards Out-group students.

The regressions in Table 4 confirm previous evidence. Moreover, we see that for fifth grade, where we have more observations, the probability of choosing the generous option is positively and significantly affected by being a close friend or a central student in the class network.

\section{TABLE 4}

REGRESSION DICTATOR GAME

\begin{tabular}{|l|c|c|}
\hline \multirow{2}{*}{ In-group } & \multicolumn{2}{|c|}{ Probability of choosing the generous action } \\
\cline { 2 - 3 } & Fourth Grade & Fifth Grade \\
\hline New-In-group & $0.340^{* * *}$ & $0.251^{* * *}$ \\
& $(0.0836)$ & $(0.0656)$ \\
\hline New-Out-group & & $0.206^{* * *}$ \\
& & $(0.0586)$ \\
\hline Degree Centrality & & $0.141^{* *}$ \\
& & $(0.0553)$ \\
\hline Friend & 0.00062 & $0.0375^{* * *}$ \\
& $(0.0237)$ & $(0.00897)$ \\
\hline Observations & -0.0227 & $0.389 * * *$ \\
\hline $\mathrm{R}^{2}$ & $(0.151)$ & $(0.0645)$ \\
\hline
\end{tabular}

NOTE: The results included in this table are marginal effects evaluated at means from a logit specification. The first column considers results for fourth grade and the second column for fifth grade. Variable Out-group is the reference category and refers to students who have never belonged to the same class as the player; variable In-group refers to students who have always belonged to the same class as the player; variable New-In- group refers to students who have never belonged to the same class as the player, but after the policy started being in the same class; and variable New-Out-group refers to students who have always belonged to the same class as the player, but after the policy stopped being in the same class. Standard errors are in parentheses and clustered at the individual level. $* p<0.10, * * p<0.05, * * * p<0.01$

SOURCE: Own elaboration based on experimental data.

${ }^{7}$ For more details about the t-tests from the difference in means in each ictator game, look at Table A1 and A2 of Section A1 in the Appendix. 


\subsection{Response Game}

The response game looks at the respondent's reactions to capture negative and positive reciprocity. Again, we first analyze if results in Chen and $\mathrm{Li}$ (2009) are also applicable to students. Namely, we test whether participants reward more and punish less when they interact with a student that has always belonged to their class relative to a student that has never been part of it. Afterwards, as in previous sections, we explore if reshuffling students is an effective measure to foster rewards and mitigate punishments.

The following logit regression investigates the effects of group identity on positive reciprocity:

$$
\operatorname{Prob}(B \text { rewards } A)=\frac{e^{(X \alpha)}}{1+e^{(X \alpha)}} \Lambda[X \alpha]
$$

where

$$
\text { Fourth Grade: } \begin{aligned}
X \alpha & =\alpha_{0}+\alpha_{1} \text { Ingroup }+\alpha_{3} \text { Benefit } A+\alpha_{4} \text { Bbehind }+ \\
& +\alpha_{5} \text { Centrality }+\alpha_{6} \text { Friend }
\end{aligned}
$$

Fifth Grade: $X \alpha=\alpha_{0}+\alpha_{1}$ Ingroup $+\alpha_{2}$ NewIngroup $+\alpha_{3}$ NewOutgroup +

$$
+\alpha_{5} \text { BenefitA }+\alpha_{6} \text { Bbehind }+\alpha_{7} \text { Centrality }+\alpha_{8} \text { Friend }
$$

and Ingroup, NewIngroup and NewOutgroup are dummies that indicate the respondent's relation with the proposer; BenefitA measures the gain in the proposer's payoff if the respondent chooses to reward; Bbehind measures how much the respondent's payoff falls behind the proposer's when the respondent chooses to reward; Centrality measures the influence of the proposer in the course network ${ }^{8}$; and Friend is a dummy that takes value 1 if the proposer is a close friend.

Analogously, for negative reciprocity:

$$
\operatorname{Prob}(B \text { punishes } A)=\frac{e^{(X \beta)}}{1+e^{(X \beta)}} \Lambda[X \beta]
$$

where

Fourth Grade: $X \beta=\beta_{0}+\beta_{1}$ Ingroup $+\beta_{2}$ Cost $+\beta_{3}$ Damage $A+\beta_{4}$ Bahead + $+\beta_{5}$ Centrality $+\beta_{6}$ Friend

Fifth Grade: $X \beta=\beta_{0}+\beta_{1}$ Ingroup $+\beta_{2}$ NewIngroup $+\beta_{3}$ NewOutgroup + $+\beta_{4}$ Cost $+\beta_{5}$ Damage $A+\beta_{6}$ Bahead $+\beta_{7}$ Centrality $+\beta_{8}$ Friend

\footnotetext{
${ }^{8}$ For more details about the way to construct these variables, look at the Section A2 in the Appendix.
} 
where DamageA measures the loss in proposer's payoff if the respondent chooses to punish, Bahead measures how much the respondent's payoff gets ahead the proposer's when the respondent chooses to punish, and Cost measures the difference in payoffs between the punishing action and the alternative.

Table 5 presents the results from the regressions for fourth and fifth grade. Panel A shows the results of the logit specifications for the determinants of positive reciprocity, whereas Panel B presents the results for the determinants of negative reciprocity. The coefficients are marginal effects evaluated at means. ${ }^{9}$

First, let us consider the determinants of positive reciprocity (see Panel A of Table 5). The analysis focuses on the main specification: Logit with centrality and friends. On average, an In-group match increases participants' likelihood to reward by 26.5 percentage points (fourth grade) and 24.3 percentage points (fifth grade) with respect to an Out-group member and this effect is significant at 1 percent level. The effect is similar in size and significance when the match is a New-In-group (23.3 percentage points) and positive, but slightly smaller, when it is a New-Out-group (11.3 percentage points). Moreover, rewards are more likely the more they benefit the proposer, if participants are interacting with a friend, or if they are interacting with someone who is very central in the network. Conversely, rewards are less likely the further behind the respondent lies with respect to the proposer after she rewards. Due to limitations in sample size, some of these effects are only significant for students in fifth grade.

Regarding negative reciprocity, we find the following (see Panel B of Table 5). An In-group match decreases participants' likelihood to punish by 17.1 (fourth grade) and 13.8 (fifth grade) percentage points with respect to an Out-group member. This effect is even more pronounced for a New-In-group match (22.3 percentage points) or a New-Out-group match (18 percentage points). All these coefficients are significant at 1 percent level. Additionally, the higher the cost of punishments or the further ahead the respondent ends up after punishing, the lower the probability to punish. Similarly, the probability to punish also decreases when students are interacting with a friend or with someone that is very central in the network. Like in the case of positive reciprocity, due to limitations in sample size, some of these effects are only significant in fifth grade. Furthermore, we find no significant effect of the size of the damage caused to the proposer on the probability to punish.

All these evidence suggests that when participants interact with someone they consider from their own group, the probability that they show positive reciprocity increases, whereas the probability they show negative reciprocity decreases. This phenomenon is reinforced when students interact with a close friend or with a popular student. After evaluating the policy intervention, we conclude that reshuffling students is an effective intervention to increase the probability to reward and mitigate the probability to punish. While participants start treating New-In-group as group members, New-Out-group students do not lose this status.

${ }^{9}$ For more details about the results in the response game, look at Table A3 and A4 of Section A1 in the Appendix. 
TABLE 5

DETERMINANTS OF RECIPROCITY

\begin{tabular}{|c|c|c|c|c|}
\hline \multirow{3}{*}{ Panel A } & \multicolumn{4}{|c|}{ Probability (B rewards A) } \\
\hline & \multicolumn{2}{|c|}{ Fourth Grade } & \multicolumn{2}{|c|}{ Fifth Grade } \\
\hline & Logit & $\begin{array}{l}\text { Logit with } \\
\text { centrality } \\
\text { and friends }\end{array}$ & Logit & $\begin{array}{l}\text { Logit with } \\
\text { centrality } \\
\text { and friends }\end{array}$ \\
\hline In-group & $\begin{array}{c}0.282 * * * \\
(0.0645) \\
\end{array}$ & $\begin{array}{c}0.265^{*} \\
(0.0694) \\
\end{array}$ & $\begin{array}{c}0.411 * \\
(0.0517) \\
\end{array}$ & $\begin{array}{c}0.243^{*} \\
(0.0508) \\
\end{array}$ \\
\hline New-In-group & & & $\begin{array}{c}0.261 * * * \\
(0.0498) \\
\end{array}$ & $\begin{array}{c}0.233^{*} \\
(0.0496) \\
\end{array}$ \\
\hline New-Out-group & & & $\begin{array}{c}0.148 * * * \\
(0.0542)\end{array}$ & $\begin{array}{l}0.113 * * \\
(0.0526)\end{array}$ \\
\hline Benefit to A if B rewards & $\begin{array}{c}0.0252 \\
(0.0183) \\
\end{array}$ & $\begin{array}{c}0.0254 \\
(0.0184) \\
\end{array}$ & $\begin{array}{c}0.0393 * * * \\
(0.00866) \\
\end{array}$ & $\begin{array}{c}0.0417 * * * \\
(0.00919) \\
\end{array}$ \\
\hline B's payoff behind of A if B rewards & $\begin{array}{c}-0.0736 * * * \\
(0.0163)\end{array}$ & $\begin{array}{c}-0.0743 * * * \\
(0.0164) \\
\end{array}$ & $\begin{array}{c}-0.0660 * * * \\
(0.00833) \\
\end{array}$ & $\begin{array}{c}-0.0711 * * * \\
(0.00899) \\
\end{array}$ \\
\hline Degree centrality & & $\begin{array}{c}-0.00868 \\
(0.0308) \\
\end{array}$ & & $\begin{array}{l}0.0188 * * \\
(0.00893) \\
\end{array}$ \\
\hline Friend & & $\begin{array}{l}0.306^{*} \\
(0.173) \\
\end{array}$ & & $\begin{array}{c}0.519 * * * \\
(0.0862) \\
\end{array}$ \\
\hline $\begin{array}{l}\text { Observations } \\
\mathrm{R}^{2} \\
\end{array}$ & $\begin{array}{c}430 \\
0.089 \\
\end{array}$ & $\begin{array}{c}430 \\
0.096 \\
\end{array}$ & $\begin{array}{r}1760 \\
0.089 \\
\end{array}$ & $\begin{array}{c}1760 \\
0.146 \\
\end{array}$ \\
\hline \multirow{3}{*}{ Panel B } & \multicolumn{4}{|c|}{ Probability (B punishes A) } \\
\hline & \multicolumn{2}{|c|}{ Fourth Grade } & \multicolumn{2}{|c|}{ Fifth Grade } \\
\hline & Logit & $\begin{array}{l}\text { Logit with } \\
\text { centrality } \\
\text { and friends }\end{array}$ & Logit & $\begin{array}{c}\text { Logit with } \\
\text { centrality } \\
\text { and friends }\end{array}$ \\
\hline In-group & $\begin{array}{c}-0.170 * * * \\
(0.0581)\end{array}$ & $\begin{array}{c}-0.171 * * * \\
-0.0608\end{array}$ & $\begin{array}{c}-0.338 * * * \\
(0.0542)\end{array}$ & $\begin{array}{c}-0.138 * * * \\
(0.0534)\end{array}$ \\
\hline New-In-group & & & $\begin{array}{c}-0.257 * * * \\
(0.0517) \\
\end{array}$ & $\begin{array}{c}-0.223 * * * \\
(0.0492) \\
\end{array}$ \\
\hline New-Out-group & & & $\begin{array}{c}-0.218 * * * \\
(0.0537) \\
\end{array}$ & $\begin{array}{c}-0.180 * * * \\
(0.0513) \\
\end{array}$ \\
\hline Cost to punish $\mathrm{A}$ & $\begin{array}{c}-0.0482^{*} \\
(0.0284) \\
\end{array}$ & $\begin{array}{c}-0.0482 * \\
(0.0283) \\
\end{array}$ & $\begin{array}{c}-0.0667 * * * \\
(0.0206)\end{array}$ & $\begin{array}{c}-0.0770 * * * \\
(0.0235)\end{array}$ \\
\hline Damage to A if B punishes & $\begin{array}{c}0.0559 \\
(0.0507) \\
\end{array}$ & $\begin{array}{c}0.0559 \\
(0.0507) \\
\end{array}$ & $\begin{array}{c}0.0104 \\
(0.0293)\end{array}$ & $\begin{array}{c}0.0118 \\
(0.0328)\end{array}$ \\
\hline B's payoff ahead of A if B punishes & $\begin{array}{c}-0.0272 \\
(0.0408) \\
\end{array}$ & $\begin{array}{l}-0.0272 \\
(0.0408) \\
\end{array}$ & $\begin{array}{c}-0.0889 * * * \\
(0.0238) \\
\end{array}$ & $\begin{array}{c}-0.102 * * * \\
(0.0269) \\
\end{array}$ \\
\hline Degree Centrality & & $\begin{array}{c}0.0157 \\
(0.0217) \\
\end{array}$ & & $\begin{array}{c}-0.0144 * * \\
(0.00724) \\
\end{array}$ \\
\hline Friend & & $\begin{array}{c}-0.0144 \\
(0.134) \\
\end{array}$ & & $\begin{array}{c}-0.486 * * * \\
(0.0656) \\
\end{array}$ \\
\hline $\begin{array}{l}\text { Observations } \\
\mathrm{R}^{2}\end{array}$ & $\begin{array}{c}344 \\
0.047 \\
\end{array}$ & $\begin{array}{c}344 \\
0.049 \\
\end{array}$ & $\begin{array}{r}1408 \\
0.063 \\
\end{array}$ & $\begin{array}{c}1408 \\
0.146 \\
\end{array}$ \\
\hline
\end{tabular}

NOTE: The results included in this table are marginal effects evaluated at means from different logit specifications. Panel A considers RG3, RG4, RG5, RG6, and RG7 response games and Panel B considers RG1, RG2, RG8, and RG9 response games. Variable Out-group is the reference category and refers to students who have never belonged to the same class as the player; variable In-group refers to students who have always belonged to the same class as the player; variable New-In-group refers to students who have never belonged to the same class as the player, but after the policy started being in the same class; and variable New-Out-group refers to students who have always belonged to the same class as the player, but after the policy stopped being in the same class. Standard errors are in parentheses and clustered at the individual level. $* p<0.10, * * p<0.05, * * * p<0.01$

SOURCE: Own elaboration based on experimental data. 
Interestingly, we find that interacting with an In-group relative to interacting with a New-Out-group or a New-In-group seems to be more effective to foster rewards, but less effective to deter punishments. Further research is necessary to understand this fact. Finally, we also find that the cost of punishing, how much the proposer benefits from rewards and how unequal the payoffs are in case of reward/punishment also have a significant impact on the probability to reciprocate.

\section{Discussion}

This paper studies whether sharing class in school generates out-group discrimination and modulates pro-social behavior. Consistent with findings in Chen and $\mathrm{Li}$ (2009) for adults, we find that when students interact with other students that have always been part of their same class, they are willing to favor them in detriment of those that have never been classmates. Moreover, when we measure their prosocial attitudes, we find that they are also more prone to share their own resources with in-groups, more willing to reward their kind actions, and more reluctant to punish their hostile behavior.

In light of these results, we also study whether reshuffling students into different groups is an effective way of fighting discrimination and enlarging the pool of children that benefit from pro-social behavior. We discover that new students in class are no longer discriminated relative to students that have always belonged to the same class. Moreover, we find that the only group that suffers discrimination is the group of students that have never been classmates, while those that were classmates in the past and are not any longer are still treated as part of the group. When we measure pro-sociality, we find that new students in class benefit from being considered part of the group, while there is small or no negative effect on those that do not belong to the group any longer. Hence, taking everything into consideration, our results suggest that schools might prevent internal ghettos and foster pro-social behaviors by modifying the class composition from time to time. To the extent that our results for fourth grade resemble those in Chen and Li (2009) for adults, it seems reasonable to think that these conclusions could be extended to other settings in which homogeneous individuals are divided into groups by superior authorities. We can find examples of such situations in other stages of education and in several work environments.

This paper should be taken as a first approximation to these phenomena and has some limitations that should be addressed in future studies. First and foremost, we cannot form a judgement about efficiency. Even though a higher degree of prosociality and lower discrimination might be desirable per se, it remains unclear what would be optimal in terms of welfare. If punishments discipline proposers to achieve more efficient outcomes, then lower average punishments towards group members might lead to inefficiencies. Moreover, we find that in some instances having shared class throughout all the courses generates a slightly different pro-social behavior 
-sometimes more intense, sometimes less. Further research is necessary to understand these differences.

Before making general policy recommendations, there are also two aspects that should be considered: How reshuffling students between classes affects their academic performance and how it affects their risk habits. There is substantial evidence that peer composition has a significant effect in drinking habits, drug use and criminal behavior, and a modest effect on academic performance (for a survey on this literature, see Sacerdote, 2011). In our study, we could not measure any effects on academic performance, as all classes were reshuffled in fifth grade. Moreover, due to the age of participants, we could not measure either any impact on risk habits. Therefore, complementary research is needed to take an informed policy decision. Finally, we also consider it could be interesting to see how these results extrapolate to other schools, as the experiment is focused on a single intervention in a private school in Barcelona.

\section{References}

Abrams, D., Palmer, S. B., Rutland, A., Cameron,L., \& Van de Vyver,J. (2014). Evaluations of and reasoning about normative and deviant ingroup and outgroup members: Development of the black sheep effect. Developmental Psychology, 50(1), 258.

Benjamin, D. J., Choi, J. J., \& Strickland, A. J. (2010). Social identity and preferences. American Economic Review, 100(4), 1913-28.

Bernhard, H., Fehr, E., \& Fischbacher, U. (2006). Group affiliation and altruistic norm enforcement. American Economic Review, 96(2), 217-221.

Bernhard, H., Fischbacher, U., \& Fehr, E. (2006). Parochial altruism in humans. Nature, 442(7105), 912.

Brewer, M. B. (1999). The psychology of prejudice: Ingroup love and outgroup hate? Journal of social issues, 55(3), 429-444.

Chen, Y., \& Li, S. X. (2009). Group identity and social preferences. American Economic Review, 99(1), 431-57.

Croson, R., Marks, M., \& Snyder, J. (2008). Groups work for women: Gender and group identity in social dilemmas. Negotiation Journal, 24(4), 411-427.

Fehr, E., Bernhard, H., \& Rockenbach, B. (2008). Egalitarianism in young children. Nature, 454(7208), 1079.

Fischbacher, U. (2007). z-tree: Zurich toolbox for ready-made economic experiments. Experimental Economics, 10(2), 171-178.

Goette, L., Huffman, D., \& Meier, S. (2006). The impact of group membership on cooperation and norm enforcement: Evidence using random assignment to real social groups. American Economic Review, 96(2), 212-216.

Goette, L., Huffman, D., \& Meier, S. (2012). The impact of social ties on group interactions: Evidence from minimal groups and randomly assigned real groups. American Economic Journal: Microeconomics, 4(1), 101-15.

Grund, T. U. (2015). Social network analysis using stata. In United Kingdom Stata Users' Group Meetings 2015, 21. Stata Users Group. 
Halevy, N., Bornstein, G., \& Sagiv, L. (2008). "In-group love" and "out-group hate" as motives for individual participation in intergroup conflict: A new game paradigm. Psychological Science, 19(4), 405-411.

Hargreaves Heap, S. P., \& Zizzo, D. J. (2009). The value of groups. American Economic Review, 99(1), 295-323.

Hartstone, M., \& Augoustinos, M. (1995). The minimal group paradigm: Categorization into two versus three groups. European Journal of Social Psychology, 25(2), 179-193.

Jordan, J. J., McAuliffe, K., \& Warneken, F. (2014). Development of in-group favoritism in children's third-party punishment of selfishness. Proceedings of the National Academy of Sciences, 111(35), 12710-12715.

Marques, J. M., Yzerbyt, V. Y., \& Leyens, J.-P. (1988). The "black sheep effect": Extremity of judgments towards ingroup members as a function of group identification. European Journal of Social Psychology, 18(1), 1-16.

Movahedi, T. (2018). Essays on group identity and social preferences (Unpublished doctoral dissertation). Department of Economics, University of Leicester.

Mullen, B., Brown, R., \& Smith, C. (1992). Ingroup bias as a function of salience, relevance, and status: An integration. European Journal of Social Psychology, 22(2), 103-122.

Rao, G. (2019). Familiarity does not breed contempt: Generosity, discrimination, and diversity in Delhi schools. American Economic Review, 109(3), 774-809.

Sacerdote, B. (2011). Peer effects in education: How might they work, how big are they and how much do we know thus far? In Handbook of the Economics of Education (Vol. 3, pp. 249-277). Elsevier.

Schmidt, M. F., Rakoczy, H., \& Tomasello, M. (2012). Young children enforce social norms selectively depending on the violator's group affiliation. Cognition, 124(3), 325-333.

Shih, M., Pittinsky, T. L., \& Ambady, N. (1999). Stereotype susceptibility: Identity salience and shifts in quantitative performance. Psychological Science, 10(1), 80-83.

Shinada, M., Yamagishi, T., \& Ohmura, Y. (2004). False friends are worse than bitter enemies: "altruistic" punishment of in-group members. Evolution and Human Behavior, 25(6), 379-393.

Sutter, M. (2009). Individual behavior and group membership: Comment. American Economic Review, 99(5), 2247-57.

Tajfel, H. (1970). Experiments in intergroup discrimination. Scientific American, 223(5), 96103.

Tajfel, H., \& Turner, J. (1979). An integrative theory of intergroup conflict. In W. G Austin $\&$ S. Worchel (Eds.), The social psychology of intergroup relations (pp. 33-47). BrooksCole Publishing.

Turner, J. C., \& Tajfel, H. (1986). The social identity theory of intergroup behavior. In W. G Austin \& S.Worchel (Eds.), Psychology of intergroup relations (pp 7-24). Nelson-Hall Publishers.

Van Vugt, M., \& Hart, C. M. (2004). Social identity as social glue: The origins of group loyalty. Journal of Personality and Social Psychology, 86(4), 585.

Zdaniuk, B., \& Levine, J. M. (2001). Group loyalty: Impact of members' identification and contributions. Journal of Experimental Social Psychology, 37(6), 502-509. 


\section{APPENDIX}

\section{A1. Tables}

TABLE A1

T-TESTS DIFFERENCES IN MEANS DICTATOR GAME (Fourth Grade)

\begin{tabular}{|c|c|c|c|}
\hline & In-group mean & Out-group mean & Difference \\
\hline \multicolumn{4}{|l|}{ Game: } \\
\hline DG1 & 0.23 & 0.12 & $\begin{array}{c}0.12 \\
(0.082) \\
\end{array}$ \\
\hline DG2 & 0.58 & 0.21 & $\begin{array}{c}0.37 * * * \\
(0.099)\end{array}$ \\
\hline DG3 & 0.72 & 0.35 & $\begin{array}{c}0.37 * * * \\
(0.101) \\
\end{array}$ \\
\hline DG4 & 0.74 & 0.30 & $\begin{array}{c}0.44 * * * \\
(0.098)\end{array}$ \\
\hline Pooled & 0.57 & 0.24 & $\begin{array}{c}0.33 * * * \\
(0.071) \\
\end{array}$ \\
\hline Observations & 43 & 43 & \\
\hline
\end{tabular}

NOTE: The table displays the t-tests from the difference on the average amount of times in which players choose option B2 when they are interacting with students from two different categories. Results are presented for each Dictator Game separated and for all the games pooled. In-group column refers to games in which the player is interacting with a student who has always belonged to the same class as the player; and Out-group column refers to games in which the player is interacting with a student who has never belonged to the same class as the player. Standard errors are in parentheses. $* p<0.10, * * p<0.05, * * * p<0.01$

SOURCE: Own elaboration based on experimental data. 
TABLE A2

T-TESTS DIFFERENCES IN MEANS DICTATOR GAME (Fifth Grade)

\begin{tabular}{|c|c|c|c|c|c|c|c|c|c|}
\hline & $\begin{array}{l}\text { In- } \\
\text { group } \\
\text { mean }\end{array}$ & $\begin{array}{l}\text { Out- } \\
\text { group } \\
\text { mean }\end{array}$ & Diff & $\begin{array}{c}\text { New } \\
\text { In-group } \\
\text { mean }\end{array}$ & $\begin{array}{l}\text { Out- } \\
\text { group } \\
\text { mean }\end{array}$ & Diff & \begin{tabular}{|c|} 
New Out- \\
group \\
mean
\end{tabular} & $\begin{array}{c}\text { Out- } \\
\text { group } \\
\text { mean }\end{array}$ & Diff \\
\hline \multicolumn{10}{|l|}{ Game: } \\
\hline DG1 & 0.38 & 0.06 & $\begin{array}{c}0.32 * * * \\
(0.058)\end{array}$ & 0.22 & 0.06 & $\begin{array}{c}0.16^{* * * *} \\
(0.051)\end{array}$ & 0.22 & 0.06 & $\begin{array}{c}0.16 * * * \\
(0.051)\end{array}$ \\
\hline DG2 & 0.63 & 0.18 & $\begin{array}{c}0.44 * * * \\
(0.066)\end{array}$ & 0.39 & 0.18 & $\begin{array}{c}0.20 * * * \\
(0.067)\end{array}$ & 0.31 & 0.18 & $\begin{array}{c}0.13 * \\
(0.064)\end{array}$ \\
\hline DG3 & 0.81 & 0.35 & $\begin{array}{c}0.45 * * * \\
(0.066)\end{array}$ & 0.53 & 0.35 & $\begin{array}{l}0.18 * * \\
(0.074)\end{array}$ & 0.48 & 0.35 & $\begin{array}{c}0.13 * \\
(0.074)\end{array}$ \\
\hline DG4 & 0.80 & 0.36 & $\begin{array}{c}0.43 * * * \\
(0.067)\end{array}$ & 0.57 & 0.36 & $\begin{array}{c}0.20 * * * \\
(0.074)\end{array}$ & 0.50 & 0.36 & $\begin{array}{c}0.14 * \\
(0.074)\end{array}$ \\
\hline Pooled & 0.65 & 0.24 & $\begin{array}{c}0.41 * * * \\
(0.051)\end{array}$ & 0.43 & 0.24 & $\begin{array}{c}0.19 * * * \\
(0.054)\end{array}$ & 0.37 & 0.24 & $\begin{array}{l}0.14^{* * *} \\
(0.053)\end{array}$ \\
\hline Observations & 88 & 88 & & 88 & 88 & & 88 & 88 & \\
\hline
\end{tabular}

NOTE: The table displays the t-tests from the difference on the average amount of times in which players choose option B2 when they are interacting with students from two different categories. Results are presented for each Dictator Game separated and for all the games pooled. In-group column refers to games in which the player is interacting with a student who has always belonged to the same class as the player; Out-group column refers to games in which the player is interacting with a student who has never belonged to the same class as the player; New-In-group column refers to games in which the player is interacting with a student who has never belonged to the same class as the player, but after the policy started being in the same class; and New-Out-group column refers to games in which the player is interacting with a student who has always belonged to the same class as the player, but after the policy stopped being in the same class. Standard errors are in parentheses. $* p<0.10, * * p<0.05$, $* * * p<0.01$

SOURCE: Own elaboration based on experimental data. 
TABLE A3

RESULTS RESPONSE GAMES (Fourth Grade)

\begin{tabular}{|l|c|c|c|c|}
\hline \multirow{2}{*}{} & \multicolumn{2}{|c|}{ In-group } & \multicolumn{2}{c|}{ Out-group } \\
\cline { 2 - 5 } & B1 & B2 & B1 & B2 \\
\hline RG1 & 0.77 & 0.23 & 0.86 & 0.14 \\
\hline RG2 & 0.56 & 0.44 & 0.86 & 0.14 \\
\hline RG3 & 0.53 & 0.47 & 0.77 & 0.23 \\
\hline RG4 & 0.40 & 0.60 & 0.67 & 0.33 \\
\hline RG5 & 0.23 & 0.77 & 0.51 & 0.49 \\
\hline RG6 & 0.63 & 0.37 & 0.74 & 0.26 \\
\hline RG7 & 0.33 & 0.67 & 0.72 & 0.28 \\
\hline RG9 & 0.23 & 0.77 & 0.21 & 0.79 \\
\hline Observations & 0.44 & 0.56 & 0.19 & 0.81 \\
\hline
\end{tabular}

NOTE: The table displays the proportion of students who choose each of the two options (B1 or B2) in the different response games. In-group columns refer to games in which the player is interacting with a student who has always belonged to the same class as the player; and Out-group columns refer to games in which the player is interacting with a student who has never belonged to the same class as the player.

SOURCE: Own elaboration based on experimental data.

TABLE A4

RESULTS RESPONSE GAMES (Fifth Grade)

\begin{tabular}{|c|c|c|c|c|c|c|c|c|}
\hline & \multicolumn{2}{|c|}{ In-group } & \multicolumn{2}{|c|}{ Out-group } & \multicolumn{2}{|c|}{ New In-group } & \multicolumn{2}{|c|}{ New Out-group } \\
\hline & B1 & B2 & B1 & B2 & B1 & B2 & B1 & B2 \\
\hline RG1 & 0.69 & 0.31 & 0.91 & 0.09 & 0.72 & 0.28 & 0.76 & 0.24 \\
\hline RG2 & 0.45 & 0.55 & 0.77 & 0.23 & 0.55 & 0.45 & 0.61 & 0.39 \\
\hline RG3 & 0.44 & 0.56 & 0.82 & 0.18 & 0.58 & 0.41 & 0.64 & 0.36 \\
\hline RG4 & 0.25 & 0.75 & 0.65 & 0.35 & 0.39 & 0.61 & 0.55 & 0.45 \\
\hline RG5 & 0.17 & 0.83 & 0.52 & 0.48 & 0.31 & 0.69 & 0.45 & 0.55 \\
\hline RG6 & 0.45 & 0.55 & 0.81 & 0.19 & 0.61 & 0.39 & 0.69 & 0.31 \\
\hline RG7 & 0.34 & 0.66 & 0.73 & 0.27 & 0.45 & 0.55 & 0.55 & 0.45 \\
\hline RG8 & 0.50 & 0.50 & 0.16 & 0.84 & 0.36 & 0.64 & 0.33 & 0.67 \\
\hline RG9 & 0.52 & 0.48 & 0.17 & 0.83 & 0.42 & 0.58 & 0.41 & 0.59 \\
\hline Observations & \multicolumn{2}{|c|}{88} & \multicolumn{2}{|c|}{88} & \multicolumn{2}{|c|}{88} & \multicolumn{2}{|c|}{88} \\
\hline
\end{tabular}

NOTE: The table displays the proportion of students who choose each of the two options (B1 or B2) in the different response games. In-group columns refer to games in which the player is interacting with a student who has always belonged to the same class as the player; Out-group columns refer to games in which the player is interacting with a student who has never belonged to the same class as the player; New-In-group columns refer to games in which the player is interacting with a student who has never belonged to the same class as the player, but after the policy started being in the same class; and New-Out-group columns refer to games in which the player is interacting with a student who has always belonged to the same class as the player, but after the policy stopped being in the same class.

SOURCE: Own elaboration based on experimental data. 


\section{A2. Degree and Eigenvector Centrality}

Based on Grund (2015)'s book and using his package of network commands for Stata, we constructed the variable degree centrality. It measures the number of times that a student is mentioned as a close friend in the pre-experiment survey. Let $Y$ be an adjacency matrix of a binary network and $Y_{i j}$ the entries in this matrix that indicate if there is a friend relationship from student $i$ to student $j\left(Y_{i j}=1\right)$ or not $\left(Y_{i j}=0\right)$. Then, the value of degree centrality assigned to student $i$ is defined as:

$$
C(i)=\sum_{j=1}^{n} Y j i
$$

\section{A3. Pre-Experiment Survey Template}

\section{Identification number}

1. Which is your class group this year: A, I o E?

2. Were you in the school last year?

3. Which was your class group last year: A, B o E?

4. How old are you?

\begin{tabular}{|l|l|}
\hline Male & Female \\
\hline & \\
\hline
\end{tabular}

5. Check with a cross your gender:

6. How many siblings do you have?

7. Do your siblings go to the same school as you? How old are them?

\begin{tabular}{|c|c|c|}
\hline Sibling & $\begin{array}{c}\text { Does he/she go to } \\
\text { the school? }\end{array}$ & How old is he/she? \\
\hline 1 & & \\
\hline 2 & & \\
\hline 3 & & \\
\hline 4 & & \\
\hline 5 & & \\
\hline
\end{tabular}


8. Do you practice any extracurricular activity in the school? Which ones? Circle them.
a) Dance in English
b) Chess
j) Gymnastics
c) Fencing
k) Tennis
d) Music
1) Choir
e) Comic
m) Orchestra
f) Sport School
n) Basket
g) Plastic arts
o) Football
h) Theatre in English
i) Theatre in French
p) Handball
q) Volleyball

9. Could you tell me who are your five best friends from the school in order? You can only mention students from fifth of primary!
1 .
2.
3 .
4.
5 .

\section{A4. Experiment Template}

This is a translation of the experimental instructions into English. The Spanish version can be provided upon request.

\section{Before the experiment}

\section{Participants are given the instructions of the games}

Good morning! My name is Marina and I am here today in order to play a game with you. The only rule of the game is that it is an individual game and you cannot talk with anyone until the end of the game. Of course, if you have any doubt, let me know and I will help you!

Now, I will propose you different games and I will ask you several questions that you will have to answer in the most honest way possible. There are not correct or incorrect answers, so you will never be wrong with your answer! Moreover, nobody will see your answers!

If everything is clear, click on CONTINUE.

\section{First Game: Other-Other Allocation Game}

\section{Participants are asked to introduce their identification number.}

Please, introduce the number that identifies you. Recall to revise you have introduced it well!

Once you have introduced it, click on CONTINUE. 
Participants are asked to divide a particular amount of sweets (10, 30 or 50 sweets) between two other participants who correspond to one of the four different categories (category $A, B, C$ or $D$ ).

Let us start the games! Imagine that you have a certain amount of sweets and you are playing with TWO other students from the school.

I will ask you to divide these sweets between these two students. Be careful, you cannot keep any of the sweets, you have to allocate all of them to the other two students.

Now, I will let you know the name of the two students between whom you have to divide the sweets.

If everything is clear, click on CONTINUE.

In order to illustrate this part of the experiment, let us consider two random names.

The two students with whom you will play this round are: Maria (Colleague 1) and Dani (Colleague 2).

If you have 10 sweets to divide, how many would you give to Colleague 1?

If you have 10 sweets to divide, how many would you give to Colleague 2?

Remember that the sum of the two quantities has to be 10!!

If you have 30 sweets to divide, how many would you give to Colleague 1?

If you have 30 sweets to divide, how many would you give to Colleague 2?

Remember that the sum of the two quantities has to be 30!!

If you have 50 sweets to divide, how many would you give to Colleague 1?

If you have 50 sweets to divide, how many would you give to Colleague 2?

Remember that the sum of the two quantities has to be 50!!

Once you have taken your decisions, click on CONTINUE.

This is the image that the students observe when the game is explained to them.

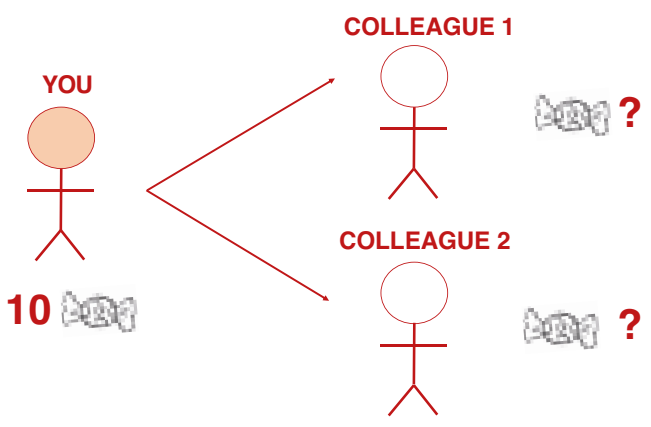


This question will be repeated for the different versions of the game.

Game 1 finishes here!

\section{Second Game: Dictator Game}

Participants are asked to introduce their identification number.

Please, introduce the number that identifies you. Recall to revise you have introduced it well!

Once you have introduced it, click on CONTINUE.

Participants are asked to choose between two particular actions that will affect another participant and themselves.

Let us start a new game! Imagine you are playing with another student from the school. Thus, consider there are two players in this game, you and another colleague.

I will ask you to decide how to share a certain amount of sweets between a colleague and yourself. This time you will not own any amount of sweets, but I will give you two options on how to share the sweets and you will have to choose one of them (OPTION B1 or OPTION B2).

Now, I will let you know the name of the student with whom you have to share the sweets and the two options.

If everything is clear, click on CONTINUE.

In order to illustrate this part of the experiment, let us consider the game DG1 in which the participants, who play the role of Player B, have to choose between option B1 and B2.

We are in the DG1 game. The student with whom you will play this round is: Maria.

Which of the two option would you choose in order to share the sweets between Maria and you, OPTION B1 or OPTION B2? Once you have taken your decision, click on CONTINUE. 
This is the image that the students observe when the game is explained to them.

\section{OPTION B1}

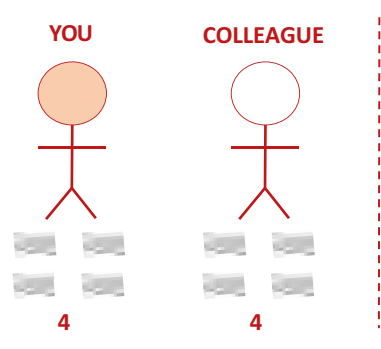

\section{OPTION B2}

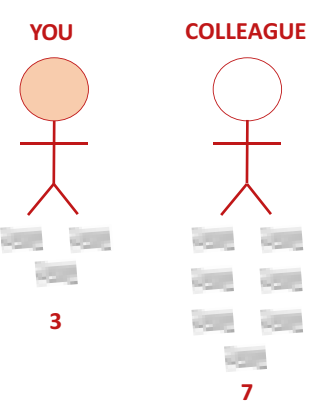

This question will be repeated for the different Dictator Games and for the different combinations of student's categories.

Game 2 finishes here!

\section{Third Game: Response Game}

Participants are asked to introduce their identification number.

Please, introduce the number that identifies you. Recall to revise you have introduced it well!

Once you have introduced it, click on CONTINUE.

Participants are asked to choose between two particular actions that will affect another participant and themselves. In this case, participants are playing $a$ sequential game with another student.

Let us start a new game! Imagine you are playing with another student from the school. Thus, consider there are two players in this game, you and another colleague. This time you will play a sequential game, meaning that your colleague plays first and afterwards it is your turn to play.

First, your colleague chooses between two options. If she chooses the first one, the game is over and your colleague decides how to share the sweets. Instead, if she chooses the second option, it will be your turn and you will be responsible to decide how to finish the game.

In this game, you will imagine that your colleague always chooses to give you the responsibility to decide how to finish the game. Be careful because being in this situation it is not necessarily good. 
First, you have to observe the decision of your colleague and understand if that choice was good or bad for you. Then, you can decide how to act in response and choose between two options on how to share the sweets, OPTION B1 or OPTION B2.

Now, I will let you know the name of the student with whom you have to share the sweets and the two options. If everything is clear, click on CONTINUE.

In order to illustrate this part of the experiment, let us consider the game RG1 in which the participants, who play the role of Player B, have to choose between option B1 and B2, assuming that Player A (their match) has previously decided to continue the game (option A2).

We are in the RGl game. The student with whom you will play this round is: Maria.

Imagine that Maria has chosen the second option: you are responsible to decide how to finish the game.

Remember, first you have to understand the intentions of your colleague: was she good or bad to you? Notice that the amount of sweets you could have obtained if your colleague had decided to finish the game before is different than the one you can obtain now.

Which of the two option would you choose in order to share the sweets between you and your colleague, OPTION B1 or OPTION B2?

Once you have taken your decision, click on CONTINUE.

This is the image that the students observe when the game is explained to them.

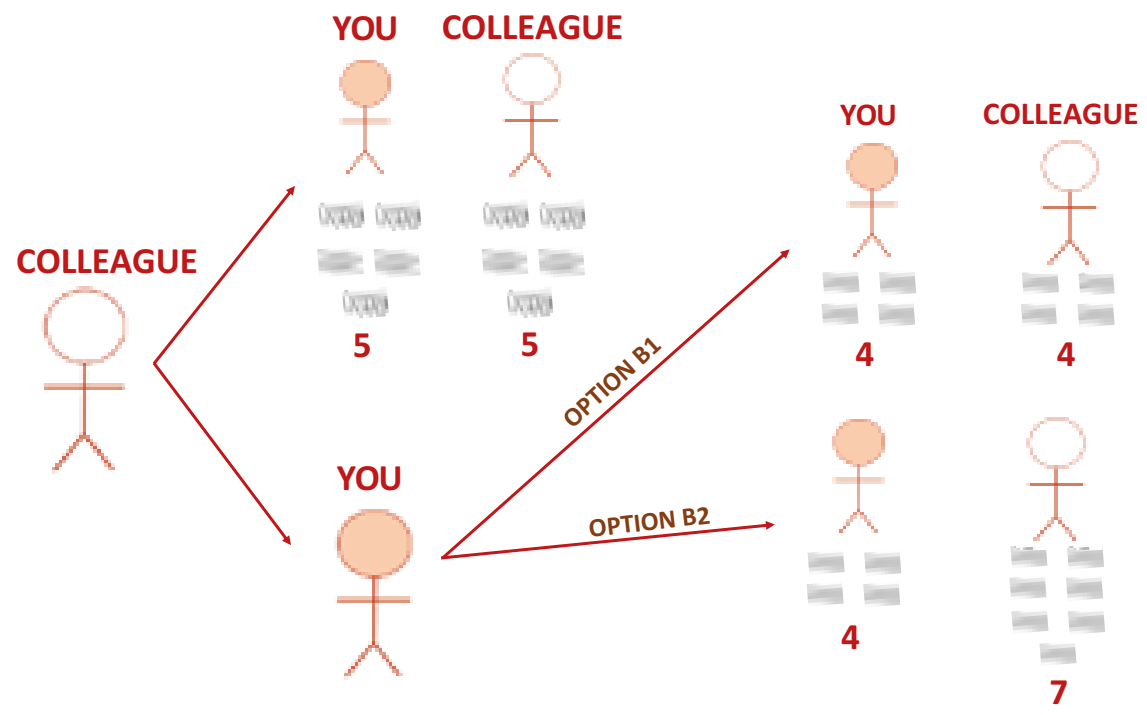


This question will be repeated for the different Response Games and for the different combinations of student's categories.

\section{Closure}

This is the end of the games!

Thank you very much for your participation!

In order to thank you for your help, you will receive 5 sweets!! 